
\title{
$\angle$ Research Square \\ Sero-epidemiology of Toxoplasma gondii and risk factors among pregnant women in Africa
}

Debora Charles Kajeguka ( $\nabla$ dkajeguka@gmail.com )

Kilimanjaro Christian Medical University College https://orcid.org/0000-0003-4341-5938

Motswedi Anderson

Botswana-Harvard AIDS Institute Partnership

Akili Mawazo

Muhimbili University of Health and Allied Sciences School of Medicine

Jacqueline James Mwakibinga

Kilimanjaro Christian Medical University College

Maseke Richard Mgabo

Institute of Rural Development Planning

Research article

Keywords: Toxoplasma gondii, pregnant women, sero-epidemiology, risk factors

Posted Date: December 13th, 2019

DOI: https://doi.org/10.21203/rs.2.18914/v1

License: (c) (i) This work is licensed under a Creative Commons Attribution 4.0 International License.

Read Full License 


\section{Abstract}

Introduction Infections caused by Toxoplasma gondii is a great public health concern worldwide. Toxoplasma gondii infection in pregnant women may result in abortion, stillbirth, or lifelong disabilities of the fetus. Serologic studies have reported various estimates for seroprevalence of toxoplasmosis among African pregnant women. Estimation of the pooled seroprevalence of this infection is necessary for policy-making and target intervention.

Methods We conducted this systematic review and meta-analysis according to the Preferred Reporting Items for Systematic Reviews and Meta-Analyses (PRISMA) statement. A rigorous literature selection was performed by using the databases of PubMed, Google Scholar, and ScienceDirect for the period Jan 1, 2001 , to July 31 , 2019. Sero-prevalence with $95 \% \mathrm{Cl}$ was presented for each study, and point estimates and their $95 \% \mathrm{Cls}$ of pooled seroprevalence was then calculated.

Findings The search process resulted in the inclusion of a total of 36 studies in the systematic review and meta-analysis. The pooled seroprevalence of Toxoplasma gondii Immunoglobulin G (IgG) in Africa was found to be $46.7 \%$ (95\%Cl: $37.0,56.4)$. Geographical-based subgroup analysis showed that the seroprevalence of T. gondii among pregnant women was found to be $65.1 \%$ ( $95 \% \mathrm{Cl}: 44.7,85.5), 50.2 \%$ (95\% Cl: $32.0,68.3), 47.8 \%$ (95\% Cl: 31.7, 63.8), 38.3\% (95\% Cl: $25.2,51.4)$ and 5.8\% (95\% Cl: 3.6, 8.1) in Central, Eastern, Northern, Western and Southern Africa respectively. The most common risk factors for T. gondii were living or contact with cat and consumption of raw vegetables or fruits.

Conclusion The current systematic review and meta-analysis revealed a high seroprevalence of Toxoplasma gondii infection among pregnant women. There is a need to establish prevention and control measures that should be directed to educational programs. We recommend that periodic screenings for Toxoplasma gondii infection among pregnant women should be incorporated into routine clinical care in order to avoid serious clinical complications of mother and fetus.

\section{Introduction}

Toxoplasma gondii (T. gondii) an apicomplexan, unicellular parasite, is one of the most common zoonoses around the world, affecting warm-blooded animals, including humans [1].

It is approximated that up to one-third of the world's human population is infected with T. gondii [2]. Moreover, T. gondii is considered as the third most common food-borne pathogen of which patients are infected [3].

Human can be infected with T. gondii through one of three ways: 1) by eating raw or undercooked meat containing T. gondii tissue cysts or eating food that has been cross-contaminated with raw/undercooked meat; 2) by ingesting oocysts from soil (through gardening, handling/eating unwashed vegetables, or infected cat feces); or 3 ) by acquiring congenital infection through the placenta $[4,5]$ when a woman gets an infection during pregnancy $[6,7]$ 
In most cases, infection in humans is asymptomatic or mild symptoms including malaise, swelling of lymph nodes and fever [8], however, when infection occurs in pregnant women several health problems can affect the fetuses, including mental retardation, blindness, epilepsy, abortion and death [1,9]. Moreover, In a systematic review and meta-analysis, it was reported that T. gondii causes severe encephalitis via acute infection or reactivation of latent infection among immune-suppressed individuals, including those with acquired immunodeficiency syndrome (AIDS), immunosuppressive cancer, and transplant recipients on immunosuppressive drugs [10].

In Africa, the prevalence of $T$. gondii among pregnant women varies greatly, the lowest prevalence has been reported in Zambia (0.6\%) [11] and the highest in Ghana (92.5\%)[12].

The wide prevalence range might be due to the different factors that might influence the probability of infection by $T$. gondii among pregnant women, these factors include environmental, socioeconomic, geographical location, health care facilities, individuals factors such as behavioral and habits [13-15]. The present systematic review and meta-analysis were therefore carried out to establish $T$. gondii seroprevalence among pregnant women, and to evaluate the possible risk factors associated with $T$. gondii seroprevalence among pregnant women across diverse settings and sampling time periods in Africa. For public health actions, understanding the prevalence and associated risk factors can aid in the analysis of the epidemiological pattern of disease among pregnant women and in Africa.

\section{Methods}

\section{Search strategy}

This study was a systematic review and meta-regression analysis of the seroprevalence of $T$. gondii and the risk of infection among pregnant women. We searched for studies in PubMed, Google Scholar, and ScienceDirect for the period Jan 1, 2001, to July 31, 2019. Checklist for Preferred Reporting Items for Systematic Reviews and Meta-Analyses (PRISMA) [16] was followed. We used the search term

"Toxoplasma gondii",','Toxoplasmosis"pregnant women", "prevalence" and seroprevalence" with the search restricted to records in English.

\section{Selection of studies}

DCK and MRM independently screened the abstracts in the search list for potentially relevant studies. Both authors compared the list of potential articles independently. DCK retrieved the full texts of the selected studies. Both DCK and MRM independently assessed published studies for inclusion, using an eligibility form based on the inclusion and exclusion criteria. Studies that met all of the eligibility criteria were included. The disagreements were resolved through discussions, or by contacting a third person who is among the authors (MA, AM, OR JJM).

Data extraction and management 
For data extraction, the detailed characteristics of each published study were extracted using a datacollection form. Information was recorded as follows: study characteristics such as the first author, year of publication, year of study, country, study design sample size; the number of the positives cases and seroprevalence of T. gondii of each study.

\section{Data analysis}

We analyzed data within sub-regions of sub-Saharan Africa: eastern Africa, southern Africa, and west and central Africa. Data were entered in Microsoft Excel and then exported to OpenMeta [Analyst] advanced software (http://www.cebm.brown.edu/openmeta) for analyses of a pooled estimate of outcome measures, as well as subgroup analysis. Heterogeneity was checked by using an $1^{2}$ test statistic. Forest plots were used to visualize the presence of heterogeneity. To confirm the results, two authors independently computed the statistical analyses and checked for uniformity. The effect size estimates were converted to odds ratios. A statistical test with a p-value less than 0.05 (one-tailed) was considered statistically significant.

\section{Findings}

\section{Characteristics of Included Studies}

The search information is summarized in Figure 1 following PRISMA guidelines [16]. We identified 161,589 articles, with 107 articles plus 11 additional articles found via reference proceeding to full-text review and finally 36 meets the inclusion criteria. Most of the studies included in this systematic review and meta-analysis had cross-sectional study design $(n=25)$, and one was retrospective and in other studies $(n=10)$ the design was not stated. The minimum sample size was 110 participants in a study conducted in Cameroon [17], while the highest sample size was 718 in a study conducted in DRC [18].

The studies qualified for the review were conducted in 12 countries in Africa. Thirteen (36.1\%) of these studies were from eastern Africa [19-31], 12 (33.3\%) from western Africa [12,32-42], 5 (13.9\%) from northern Africa [43-47], five (13.9\%) from central Africa [17,18,48-50] and one (2.8\%) were from southern Africa [11]. The overall number of study participants included in this meta-analysis was 10,701 and 4,242 pregnant women for IgG and IgM respectively.

\section{The pooled prevalence of Toxoplasmosis based in IgG measurement}

Thirty-six published studies were included in this systematic review and meta-analysis and all of these studies were used to estimate the pooled prevalence of $T$. gondii among pregnant women as measured by IgG. The minimum prevalence of anti- $T$. gondii IgG was $0.6 \%$ and it was found in Zambia [11]. On the other hand, the maximum T. gondii prevalence was found to be $92.5 \%$ in a study conducted in Ghana [12]. Using the random effect analysis, the pooled prevalence of $T$. gondii among pregnant women in Africa was $46.7 \%\left(95 \% \mathrm{Cl}(37.0,56.4)\right.$. The $\mathrm{I}^{2}$ test result showed high heterogeneity $\left(\mathrm{I}^{2} 99.3 \%, \mathrm{P}=<0.000\right)$, Figure 1 
Sub-group analysis showed that the seroprevalence of $T$. gondii among pregnant women was found to be $50.2 \%$ (95\% Cl: 32.0, 68.3), 38.3\% (95\% Cl: 25.2, 51.4), 65.1\% (95\% Cl: 44.7, 85.5), 5.8\% (95\% Cl: 3.6, 8.1) and $47.8 \%(95 \% \mathrm{Cl}: 31.7,63.8)$ in Eastern, Western, Central, Southern and Northern Africa respectively, (Figure 2).

\section{The pooled prevalence of Toxoplasmosis based in IgM measurement}

Eighteen published studies were included in the meta-analysis to estimate the pooled prevalence of $T$. gondii among pregnant women as measured by IgM. Likewise, the minimum prevalence of anti- T. gondii IgM was $0.7 \%$ in a study conducted in Tanzania [19] while the maximum $T$. gondii seroprevalence was found to be $76.1 \%$ in a study conducted in Ghana [12]. The pooled prevalence of $T$. gondii among pregnant women in Africa was $8.40 \%\left(95 \% \mathrm{Cl}(5.20,11.6)\right.$. The $\mathrm{I}^{2}$ test result showed high heterogeneity $\left(I^{2} 96.7 \%, P=<0.000\right)$, Figure 3

Subgroup analysis showed varied seroprevalence of $T$. gondii in four geographical zones of Africa with the highest and lowest prevalence observed in Western 14.8\% (95\% Cl: 5.6, 24.0) and Central 2.7\% (95\% Cl: $0.3 \%-5.8$ ), respectively (Figure 4 ).

\section{Discussion}

The objective of the present systematic review and meta-analysis was to assess the seroprevalence of $T$. gondii infection and associated risk factors among pregnant women in Africa. T. gondii infection during pregnancy results in mental retardation, premature birth, low birth weight, blindness, epilepsy, and death [9]. Moreover a number of published studies have shown that $T$. gondii infection in pregnancy is associated with increased risk of miscarriages, hearing loss, hematological abnormalities and death as a major determinant of infant mortality and increased risk of maternal morbidity and mortality [51-53].

\section{Pooled Prevalence}

In a meta-analysis, the pooled prevalence of $\lg G$ against $T$. gondii infections among pregnant women in Africa was $46.7 \%$. This is higher than the study conducted in China and Iran which showed a seroprevalence of $5.0 \%$ [54] and 38\% [55] respectively among pregnant women. However, relatively similar seroprevalence (41.3\%) has been reported in Iranian pregnant women [56]. The high seroprevalence of $T$. gondii among pregnant women could be due to decreased immunity and physiological changes during pregnancy, decreased awareness, as well as increased risk of exposure.

\section{Risk factors}

In this review, a number of studies reported the assessment of risk factors of $T$. gondii infection in pregnant women. Cat is the final host of T. gondii and various warm-blooded animals and humans are the intermediate hosts. It is reported that the sexual multiplication of T. gondii takes place in cats and hence cats excrete the unsporulated oocysts with faeces in the environments $[4,57]$. Living or contact with 
cat were found to be the independent predictors of $T$. gondii infection $(p<0.05)[11,21,23,27,29,34]$. Whereas only one study did not find any association of living or contact with domestic animals such as cat and being infected with $T$. gondii among pregnant women [45]. As per the WHO recommendations on the prevention of $T$. gondii infections; hygiene including hand-washing and the use of clean water in food production and preparation is critical. Pregnant women should avoid undercooked meat [58]. Moreover, It is advisable that pregnant women wear gloves when gardening and during contact with soil or sand because they might be contaminated with cat feces that contain Toxoplasma [58].

In this review, other predictors of $T$. gondii seropositivity were the consumption of raw vegetables or fruits. A significant association was observed between $T$. gondii seropositivity and eating raw or unwashed vegetables or fruits $[20,21,28,30,35,37,44]$.

\section{Continue Health Education for toxoplasmosis control}

Reviewed studies concluded that there is the need of implanting a community education among pregnant women $[11,21,22,27-30,33,35,44,46,50]$. Since there is no vaccine against $T$. gondii, prevention depends only on increasing the pregnant women's knowledge about toxoplasmosis, its origin, transmission and prevention. Education programs are inevitability needed for the improvement of basic concepts of toxoplasmosis control and prevention. More importantly, continued and improved knowledge and access to reliable information about sources of infection are suitable to consequently change women's behavior during pregnancy $[59,60]$ and also in their everyday life.

\section{Limitation}

This review contains some limitations, which should be discussed. Some studies had limited sample size that may not necessarily have represented the country or national seroprevalence. Studies used a variety of serological diagnostic methods that have a different range of sensitivities and specificities, and they used different cutoff levels in defining positive results. Most of the studies in this review employed crosssectional study designs, which means that it is hard to establish a causal relationship between the risk factors they identified and T. gondii infection among pregnant women.

\section{Implications for policy practice}

Based on the current review, pregnant women still have a greater risk of T. gondii infection. T. gondii infection is often ignored or not diagnosed or insufficiently reported in many African countries. In addition to the effort of improving women and child health, policymakers may wish to consider improving diagnosis of T. gondii in African settings. Thus, community education of pregnant women and general population would effectively combat T. gondii in Africa.

\section{Implication for Research}

Different risk factors particularly consumption of raw or unwashed/ not well-washed vegetables or fruits, staying or contact with cats are highly correlated and influence on Toxoplasma gondii. Future studies 
may collect data on follow-up studies and develop a comprehensive valid and reliable measure to be used for analyzing the cause of risk factors on Toxoplasma gondii. Moreover, intervention studies that involve provision of health education about Toxoplasma gondii and evaluation any changes in the risk of infection that might be observed.

\section{Conclusion}

The current systematic review and meta-analysis showed that the pooled prevalence of T. gondii in Africa among pregnant women is relatively higher compared with the other review and meta-analysis conducted in other parts of the world. Therefore, there is a need to establish prevention and control measures that should be directed to educational programs. We recommend that periodic screenings for $T$. gondii infection among pregnant women should be incorporated into routine clinical care in order to avoid serious clinical complications of mother and fetus.

\section{List Of Abbreviations}

AIDS: acquired immunodeficiency syndrome

IgG: Immunoglobulin G

IgM: Immunoglobulin M

PRISMA: Systematic Reviews and Meta-Analyses

WHO: World health organization

\section{Declarations}

Ethics approval and consent to participate

Not applicable.

Consent for publication

Not applicable.

Availability of data and materials

Data will be available upon request to the corresponding author.

Competing interests

None to declare

Funding 
No funding was obtained for this study.

\section{Authors' contributions}

DCK developed the protocol and involved in the design, selection of study, data extraction, statistical analysis and developing the initial drafts of the manuscript.

MRM Involved in data extraction, quality assessment, statistical analysis.

JJM prepared and revising subsequent drafts

AM prepared and revising subsequent drafts

MA prepared and edited the final draft of the manuscript.

All authors read and approved the final draft of the manuscript.

Acknowledgments

We would like to thank all authors of studies included in this systematic review and meta-analysis.

\section{Reference}

1. Dubey J. Toxoplasmosis of Animals and Humans. Second Edi. Boca Raton, FL: CRC Press; 2010.

2. Zhou P, Chen Z, Li H, Zheng H, He S, Lin R, et al. Toxoplasma gondii infection in humans in China. Parasites. 2011;4(165):1-9.

3. Vaillant V, Valk HDE, Baron E, Ancelle T, Colin P, Delmas M, et al. Foodborne Infections in France. Foodborne Pathog Dis. 2005;2(3).

4. Jones JL, Kruszon-moran D, Wilson M, Mcquillan G, Navin T, Mcauley JB. Toxoplasma gondii Infection in the United States: Seroprevalence and Risk Factors. Am J Epidemiol. 2001;154(4):35765.

5. Montazeri M, Mehrzadi S, Sharif M, Sarvi S. Drug Resistance in Toxoplasma gondii. Front Microbiol. 2018;9(2687).

6. Moncada PA, Montoya JG. Toxoplasmosis in the fetus and newborn: an update on prevalence, diagnosis and treatment. Expert Rev Anti Infect Ther. 2012;10(7):815-28.

7. Sepu'lveda-Arias J, Go'mez-Marin JE, Bobic B, Naranjo-Galvis CA, Djurkovic-Djakovi O. Toxoplasmosis as a travel risk. Travel Med Infect Dis. 2014;05:1-10.

8. Joyson D, Wreghitt T. Toxoplasmosis: a comprehensive clinical guide. The Edinburgh Building, Shaftesbury Road, Cambridge CB2 2RU,United Kingdom: Cambridge University Press; 2003. 410 p.

9. Jeffrey Jones, M. D., Adriana Lopez., and Marianna Wilson MS. Congenital Toxoplasmosis. Am Fam Physician. 2003;67(10):2131-8. 
10. Wang Z, Liu H, Ma Z, Ma H, Li Z, Yang Z-B, et al. Toxoplasma gondii Infection in Immunocompromised Patients: A Systematic Review and Meta Analysis. Front Microbiol. 2017;8(March):1-12.

11. Frimpong C, Makasa M, Sitali L, Michelo C. Seroprevalence and determinants of toxoplasmosis in pregnant women attending antenatal clinic at the university teaching hospital, Lusaka, Zambia. BMC Infect Dis. 2017;17(10):1-8.

12. Ayi I, Edu SAA, Boamah D, Bosompem KM, Edoh D. Sero-epidemiology of Toxoplasmosis amongst pregnant women in the greater Accra region of Ghana. Ghana Med J. 2009;43(3):107-14.

13. Muñoz-Zanzi CA, Fry P, Lesina B, Hill D. Toxoplasma gondii Oocyst-specific antibodies and source of infection. Emerg Infect Dis. 2010;16(10):1591-1593.

14. Iddawela D, Vithana SMP, Ratnayake C. Seroprevalence of toxoplasmosis and risk factors of Toxoplasma gondii infection among pregnant women in Sri Lanka: A cross sectional study. BMC Public Health. 2017;17(930):1-6.

15. Robert-Gangneux F, Dardé ML. Epidemiology of and diagnostic strategies for toxoplasmosis. Clin Microbiol Rev. 2012;25(2):264-296.

16. Moher D, Liberati A, Tetzlaff J, Altman DG. Preferred Reporting Items for Systematic Reviews and Meta-Analyses: The PRISMA Statement. Ann Intern Med. 2009;151(4):264-9.

17. Njunda AL, Assob JCN, Nsagha DS, Kamga HL, Nde PF, Yugah VC. Seroprevalence of Toxoplasma gondii among pregnant women in Cameroon. J Public Health Africa. 2011;2(24):98-100.

18. Yobi D, Piarroux R, L'Ollivier C, Franck J, Situakibanza H, Muhindo H, et al. Toxoplasmosis among pregnant women:High seroprevalence factors in Kinshasa, Democratic Republic of Congo. Asian Pac J Trop Biomed. 2014;4(1):69-74.

19. Shao ER, Ndazana SG, Chacha W, Masenga G, Tolbert S, Mosha D, et al. Sero-Prevalence and Factors Associated with Toxoplasma Gondii Infection among Pregnant Women Attending Antenatal Care in the Referral Hospital in Tanzania: Cross Sectional Study. Ann Clin Laboratoty Res. 2015;3(2:17):1-6.

20. Paul E, Kiwelu I, Mmbaga B, Nazareth R, Sabuni E, Maro A, et al. Toxoplasma gondii seroprevalence among pregnant women attending antenatal clinic in Northern Tanzania. Trop Med Health. 2018;46(39):1-8.

21. Teweldemedhin M, Gebremichael A, Geberkirstos G, Hadush H, Gebrewahid T, Asgedom SW, et al. Seroprevalence and risk factors of Toxoplasma gondii among pregnant women in Adwa district, northern Ethiopia. BMC Infect Dis. 2019;19(327):1-9.

22. Awoke K, Endalkachew N, Munshea A. Sero-prevalence and associated risk factors of Toxoplasma gondii infection among pregnant women attending antenatal care at Felege Hiwot Referral Hospital, northwest Ethiopia. Asian Pac J Trop Med. 2015;8(7):549-54.

23. Endris M, Belyhun Y, Moges F, Adefiris M, Tekeste Z, Mulu A, et al. Seroprevalence and Associated Risk Factors of Toxoplasma gondii in Pregnant Women Attending in Northwest Ethiopia. Iran $\mathrm{J}$ Parasitol. 2014;9(3):407-14. 
24. Mwambe B, Mshana SE, Kidenya BR, Massinde AN, Mazigo HD, Michael D, et al. Sero-prevalence and factors associated with Toxoplasma gondii infection among pregnant women attending antenatal care in Mwanza,Tanzania. Parasit Vectors. 2013;6(222):1-5.

25. Murebwayire E, Njanaake K, Ngabonziza JCS, Jaoko W. Seroprevalence and risk factors of Toxoplasma gondii infection among pregnant women attending antenatal care in Kigali, Rwanda. Tanzan J Health Res. 2017;19(1):1-9.

26. Sitoe SP., Rafael B, Meireles L., Andrade, H F, Thompson R. Preliminary report of HIV and Toxoplasma gondii occurrence in pregnant women from Mozambique. Rev Inst Med Trop São Paulo. 2010;52(6):291-5.

27. Zemene E, Yewhalaw D, Abera S, Belay T, Samuel A, Zeynudin A. Seroprevalence of Toxoplasma gondii and associated risk factors among pregnant women in Jimma town, Southwestern Ethiopia. BMC Infect Dis. 2012;12(337):1-6.

28. Negero J, Yohannes M, Tegegne D. Seroprevalence and potential risk factors of T. gondii infection in pregnant women attending antenatal care at Bonga Hospital, Southwestern Ethiopia. Int J Infect Dis. 2017;57:44-9.

29. Abamecha F, Awel H. Seroprevalence and risk factors of Toxoplasma gondii infection in pregnant women following antenatal care at Mizan Aman General Hospital, Bench Maji Zone ( BMZ), Ethiopia. BMC Infect Dis. 2016;16(460):1-8.

30. Yohanes T, Zerdo Z, Chufamo N, Abossie A. Seroprevalence and Associated Factors of Toxoplasma gondii Infection among Pregnant Women Attending in Antenatal Clinic of Arba Minch Hospital, South Ethiopia: Cross Sectional Study. Transl Biomed. 2017;8(1):1-7.

31. Gelaye W, Kebede T, Hailu A. High prevalence of anti-toxoplasma antibodies and absence of Toxoplasma gondii infection risk factors among pregnant women attending routine antenatal care in two Hospitals of Addis Ababa, Ethiopia. Int J Infect Dis [Internet]. 2015;34:41-5. Available from: http://dx.doi.org/10.1016/j.ijid.2015.03.005

32. Bamba S, Sourabie Y, Guiguemde T., Karou D., Simpore J, Bambara M, et al. Seroprevalence of Latent Toxoplasma gondii Infection among HIV infetced Pregnant Women in Bobo-Dioulasso, Burkina Faso. Pakstan J Biol Sceinces. 2014;17(9):1074-8.

33. Bamba S, Cissé M, Sangaré I, Zida A, Ouattara S, Guiguemdé RT. Seroprevalence and risk factors of Toxoplasma gondii infection in pregnant women from Bobo Dioulasso, Burkina Faso. BMC Infect Dis. 2017;17(482):1-6.

34. Yusuf A., Yahaya S, Akande-Azeez O. Seroprevalence and risk factors of toxoplasma gondii infection (toxoplasmosis) among hiv seropositive pregnant women in a tertiary healthcare centre, Kano, Northern Nigeria. J Med Med Sci Vol. 2016;7(1):1-5.

35. Deji-Agboola A., Busari OS, Osinupebi OA, Amoo AOJ. Seroprevalence of Toxoplasma gondii Antibodies among Pregnant Women Attending Antenatal Clinic of Federal Medical Center, Lagos, Nigeria. Int J Biol Med Res. 2011;2(4):1135-9. 
36. Ayi I, Sowah AO, Blay EA, Suzuki T, Ohta N, Ayeh-kumi PF. Toxoplasma gondii infections among pregnant women, children and HIV-seropositive persons in Accra, Ghana. Trop Med Health. 2016;44(17):1-8.

37. Dairo MD, Ogunjimi T, Ayinmode AB. Knowledge, Risk Factors and Prevalence of Toxoplasmosis Among Pregnant Women at Primary Health Care Level in Ibadan, Southwestern Nigeria. Afr J Biomed Res. 2018;21:267-71.

38. Abdullahi IN, Hafeez A. Prevalence and Associated Risk Factors of Toxoplasma gondii Antibodies among Pregnant Women Attending Maiduguri Teaching. J Med Sci. 2015;15(3):147-54.

39. Linguissi LSG, Nagalo BM, Bisseye C, Kagoné TS, Sanou M, Tao I, et al. Seroprevalence of toxoplasmosis and rubella in pregnant women attending antenatal private clinic at Ouagadougou, Burkina Faso. Asian Pac J Trop Biomed. 2012;2012:810-3.

40. Quermi D, Simpore J, Belem AM., D.S S, Ilboudo D, Bisseye C, et al. Co-infection of Toxoplasma gondii with HBV in HIV Infected and Uninfected Pregnant Women in Burkina Faso. Pakstan J Biol Sceinces. 2009;12(17):1188-93.

41. Wokem GN, Onosakponome E, Arene FO. Toxoplasmosis among pregnant women attending antenatal clinic in a health facility in Port Harcourt, Rivers State, Nigeria. Niger J Parasitol. 2018;39(1).

42. Akinbam A, Adewunmi A., Rabiu K, Wright K, AO D, MO D, et al. Seroprevalence of Toxoplasma gondii antibodies amongst pregnant women at Lagos State University Teaching Hospital. Niger Postgr Med J. 2010;17(2):164-7.

43. Mousa DA, Mohammad MA, Toboli AB. Toxoplasma gondii infection in pregnant women with previous adverse pregnancy outcome. Med J Islam World Acad Sci. 2011;19(2):95-102.

44. Deeb H., Hesham S, Khodeer S, Azza A. Prevalence of Toxoplasma gondii infection in antenatal population in Menoufia. Acta Trop. 2012;124(3):185-91.

45. Bassiouny HK, Soliman NK, Tawab S El, Eassa SM, Eissa A, Tawab S El. Sero-prevalence and risk factors associated with toxoplasma gondii infection among pregnant women in Alexandria, Egypt. Int J Reprod Contraception, Obstet Gynecol. 2016;5(12):4220-7.

46. El-Shqanqery H, Ibrahim HM, Mohamed A., El-sharawy A. Seroprevalence of Toxoplasma gondii infection and associated risk factors among asymptomatic pregnant females in Egypt. J Egypt Soc Parasitol. 2017;47(1):93-100.

47. Kamal AM, Ahmed AK, Abdellatif MZM, Tawfik M, Hassan EE. Seropositivity of Toxoplasmosis in Pregnant Women by ELISA at Minia University Hospital, Egypt. Korean J Parasitol. 2015;53(5):60510.

48. Mabeku LB., Tchakounte C, Bonsi ST, Etoa F. Prevalence of Toxoplasma gondii and Associated Risk Factors among Pregnant Women Attending Hospital Centers in Penka-Michel, Cameroon. J Sci Res Reports. 2018;21(2):1-11.

49. Njunga A, Dickson N, Assob J-C, Kamga H-L, Tafili R, Achidi E. Seroepidemiology of Toxoplasmosis in Pregnant Women Attending the University Teaching Hospital in Yaounde, Cameroon. Int J Heal 
Res. $2011 ; 4(1): 1-9$.

50. Nguefack CT, Meumeu IK, Ngaba, Pascal G, Kongnyuy E, Njamen TN, Mboudou HEG, et al.

Prevalence and Factors Associated with Toxoplasma Gondii Immunization among Pregnant Women in Douala-Cameroon. J Women ' s Heal, Issues Care. 2016;5(4).

51. Findal G, Helbig A, Haugen G, Jenum PA, Stray-Pedersen B. Management of suspected primary Toxoplasma gondii infection in pregnant women in Norway: Twenty years of experience of amniocentesis in a low-prevalence population. BMC Pregnancy Childbirth. 2017;17(1):1-9.

52. Montoya JG, Remington JS. Management of Toxoplasma gondii Infection during Pregnancy. Clin Infect Dis. 2008;47(4):554-66.

53. Li XL, Wei HX, Zhang H, Peng HJ, Lindsay DS. A meta analysis on risks of adverse pregnancy outcomes in Toxoplasma gondii infection. PLoS One. 2014;9(5):1-12.

54. Deng H, Devleesschauwer B, Liu M, Li J, Wu Y, Van Der Giessen JWB, et al. Seroprevalence of Toxoplasma gondii in pregnant women and livestock in the mainland of China: A systematic review and hierarchical meta-Analysis. Sci Rep [Internet]. 2018;8(6218):1-10. Available from: http://dx.doi.org/10.1038/s41598-018-24361-8

55. Foroutan-Rad M, Khademvatan S, Majidiani H, Aryamand S, Rahim F, Malehi AS. Seroprevalence of Toxoplasma gondii in the Iranian pregnant women: A systematic review and meta-analysis. Acta Trop [Internet]. 2016;158:160-9. Available from: http://dx.doi.org/10.1016/j.actatropica.2016.03.003

56. Malary M, Moghaddasifar I, Hamzehgardeshi Z, Moosazadeh M, Kheradmand M, Afshari M, et al. Seroprevalence of Toxoplasma gondii infection among Iranian pregnant women: A systematic review and meta-analysis. East Mediterr Heal J. 2018;24(5):488-96.

57. Jones JL, Krueger A, Schulkin J, Schantz PM. Toxoplasmosis prevention and testing in pregnancy, survey of obstetrician-gynaecologists. Zoonoses Public Health. 2010;57(1):27-33.

58. WHO. Toxoplasmosis Fact Sheet: WHO estimates of the Global Burden of Food Borne Diseases [Internet]. World Health Organisation. 2015 [cited 2019 Jul 15]. Available from: http://www.euro.who.int/_data/assets/pdf_file/0011/294599/Factsheet-Toxoplasmosis-en.pdf?ua $=1$

59. Di Mario S, Basevi V, Gagliotti C, Spettoli D, Gori G, D’Amico R, et al. Prenatal education for congenital toxoplasmosis. Cochrane Database Syst Rev. 2015;(10).

60. Pawlowski ZS, Gromadecka-Sutkiewicz M, Skommer J, Paul M, Rokossowski H, Suchocka E, et al. Impact of health education on knowledge and prevention behavior for congenital toxoplasmosis: the experience in Poznan, Poland. Health Educ Res. 2001;16(4):493-502.

\section{Figures}



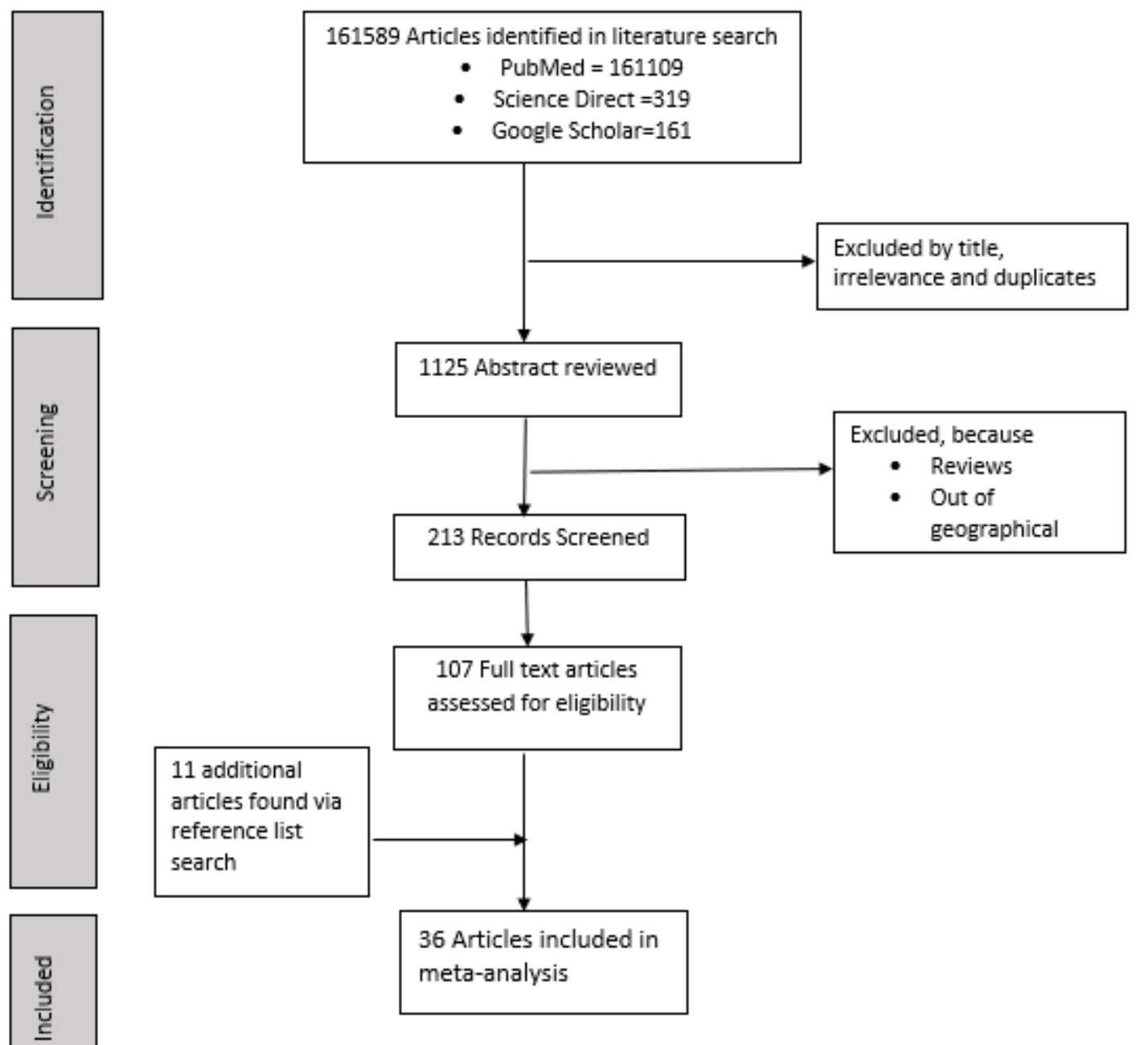

\section{Figure 1}

Flow chart of the selection process 
Name of Publication

Teweldemedhin 2019

Paul 2018

Wokem 2018

Dairo 2018

Mabeku 2018

Yohanes 2017

Negero 2017

Murebwayire 2017

Bamba(b) 2017

Frimpong 2017

Yusuf 2016

Ayi(b) 2016

Nguefack 2016

Gelaye 2015

Shao 2015

Kamal 2015

Nasir 2015

Awoke 2015

Endris 2014

Yobi 2014

Bamba(a) 2014

Mwambe 2013

Deeb 2012

Linguissi 2012

Njunda(a) 2011

Mousa 2011

Deji-Agboola 2011

Njunda(b) 2011

Sitoe 2010

Akinbami 2010

Quirmi 2009

Ayi(a) 2009
El-Shqanqery 2017

Bassiouny 2016

Abamecha 2016

Zemene 2012

Estimates (95\% CI) Prevalence/Total

$0.325(0.277,0.373)$

$0.402(0.341,0.462)$

$117 / 360$

$0.225(0.169,0.281)$

$0.358(0.310,0.406)$

$0.358(0.321,0.395)$

$0.754(0.699,0.810)$

$0.757(0.699,0.815)$

$0.096(0.067,0.126)$

$0.310(0.259,0.361)$

$0.058(0.036,0.081)$

$0.302(0.267,0.336)$

$0.308(0.253,0.362)$

$0.579(0.529,0.628)$

$0.512(0.424,0.600)$

$0.786(0.741,0.830)$

$0.823(0.774,0.872)$

$0.854(0.813,0.895)$

$0.417(0.336,0.497)$

$0.383(0.296,0.470)$

$0.400(0.349,0.451)$

$0.185(0.146,0.224)$

$0.886(0.854,0.917)$

$0.803(0.775,0.831)$

$0.348(0.298,0.398)$

$0.309(0.260,0.357)$

$0.527(0.458,0.596)$

$0.675(0.624,0.726)$

$0.203(0.145,0.262)$

$0.700(0.614,0.786)$

$0.448 \quad(0.366,0.529)$

$0.326(0.271,0.381)$

$0.609(0.518,0.700)$

$0.187(0.124,0.249)$

$0.408(0.336,0.480)$

$0.272(0.219,0.324)$

$0.925(0.883,0.966)$

Overall (I^2=99.36\%, P< 0.001) $0.467 \quad(0.370,0.564)$
$102 / 254$

$48 / 213$

$135 / 377$

$230 / 643$

$175 / 232$

$159 / 210$

$37 / 384$

$98 / 316$

$24 / 411$

$209 / 693$

$84 / 273$

$221 / 382$

$64 / 125$

$257 / 327$

$191 / 232$

$246 / 288$

$60 / 144$

$46 / 120$

$144 / 360$

$71 / 384$

$341 / 385$

$627 / 781$

$121 / 348$

$108 / 350$

$106 / 201$

$218 / 323$

$37 / 182$

$77 / 110$

$64 / 143$

$90 / 276$

$67 / 110$

$28 / 150$

$73 / 179$

$75 / 276$

$147 / 159$

4897/10701
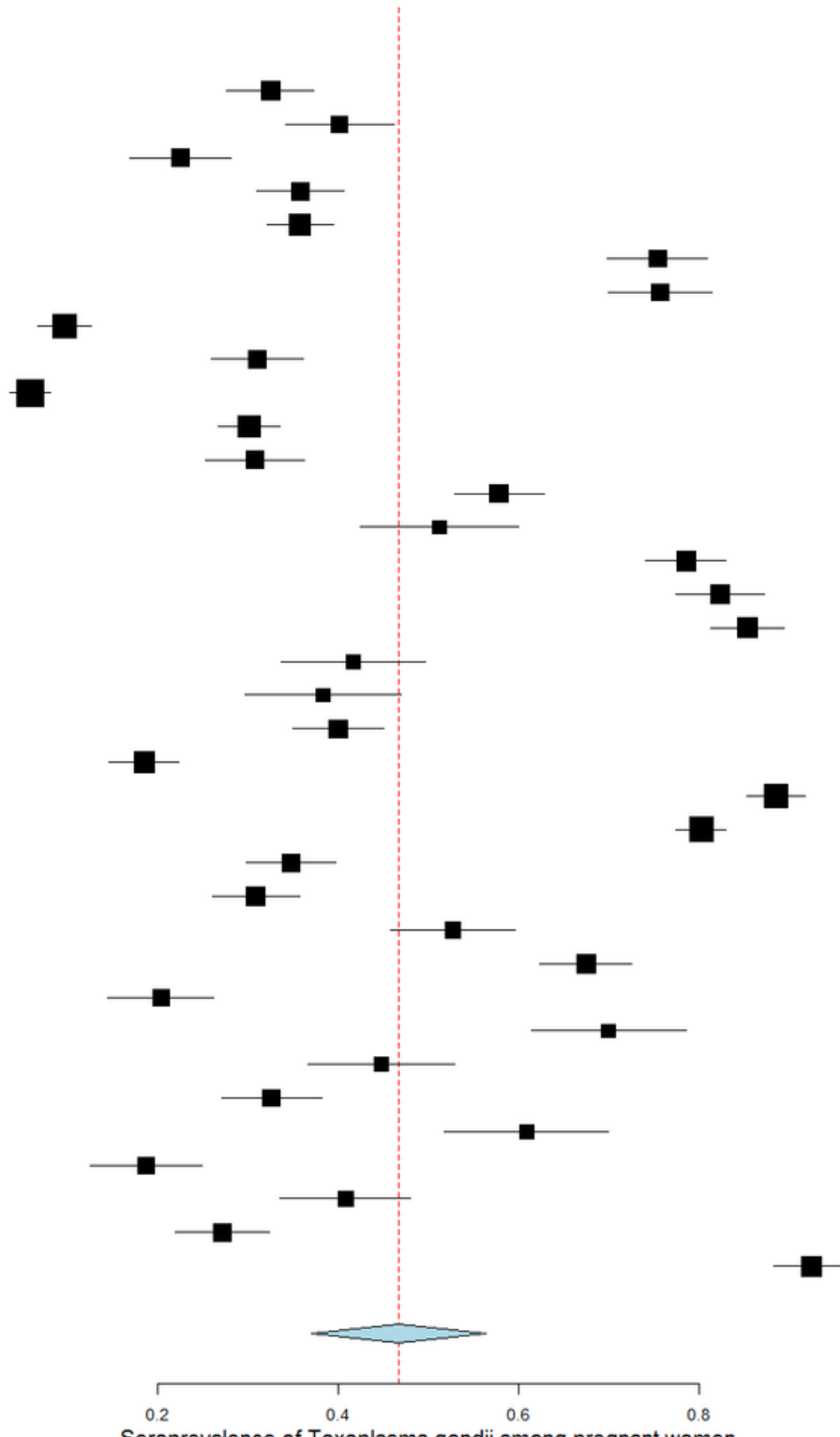

Seroprevalence of Toxoplasma gondii among pregnant women

\section{Figure 2}

Forest Plot depicting the pooled analysis of 36 studies reporting Seroprevalence of T. gondii among pregnant women measured by lgG 


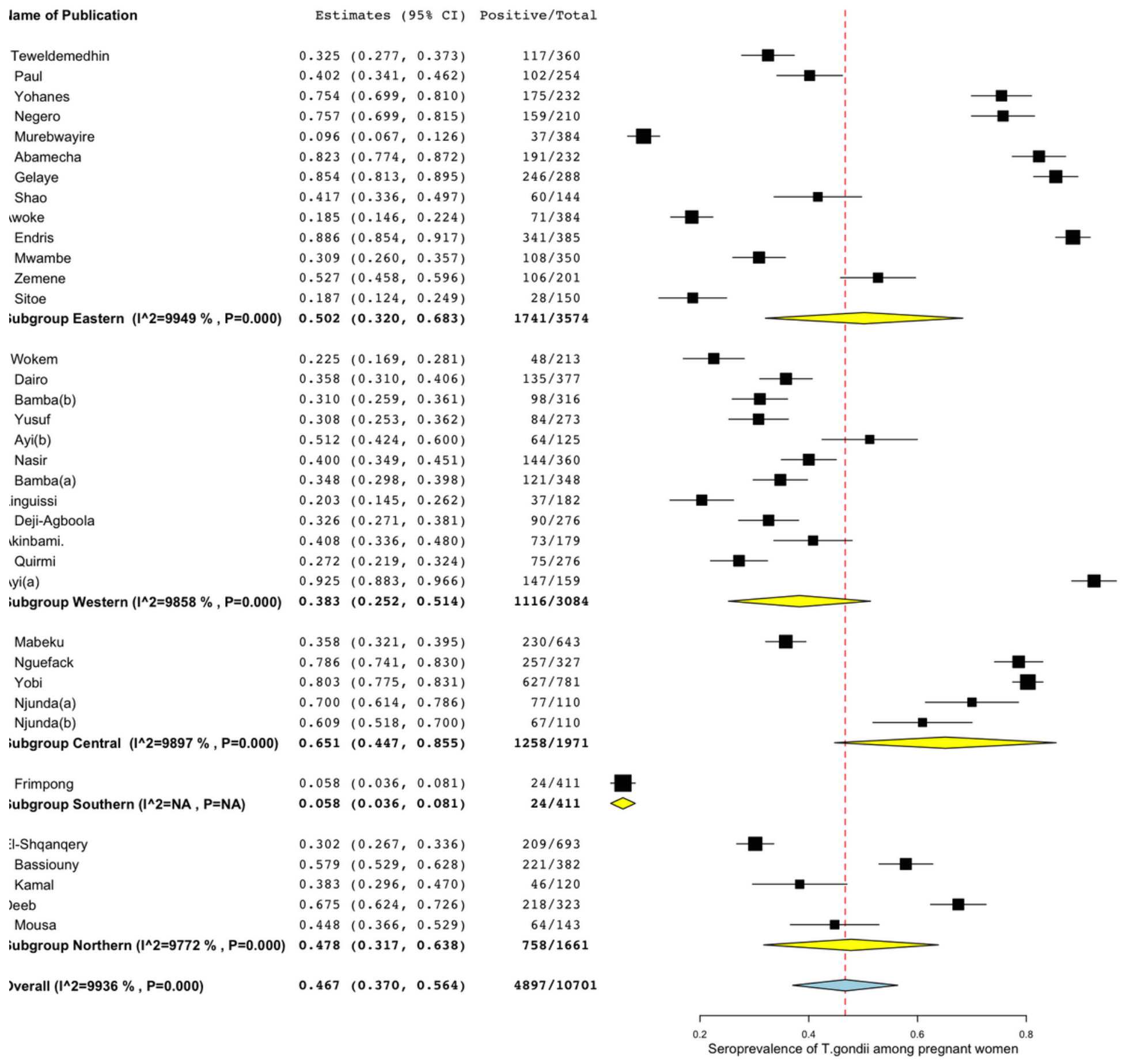

Figure 3

Forest plot depicting sub-group analysis of T. gondii among pregnant women measured by IgG 


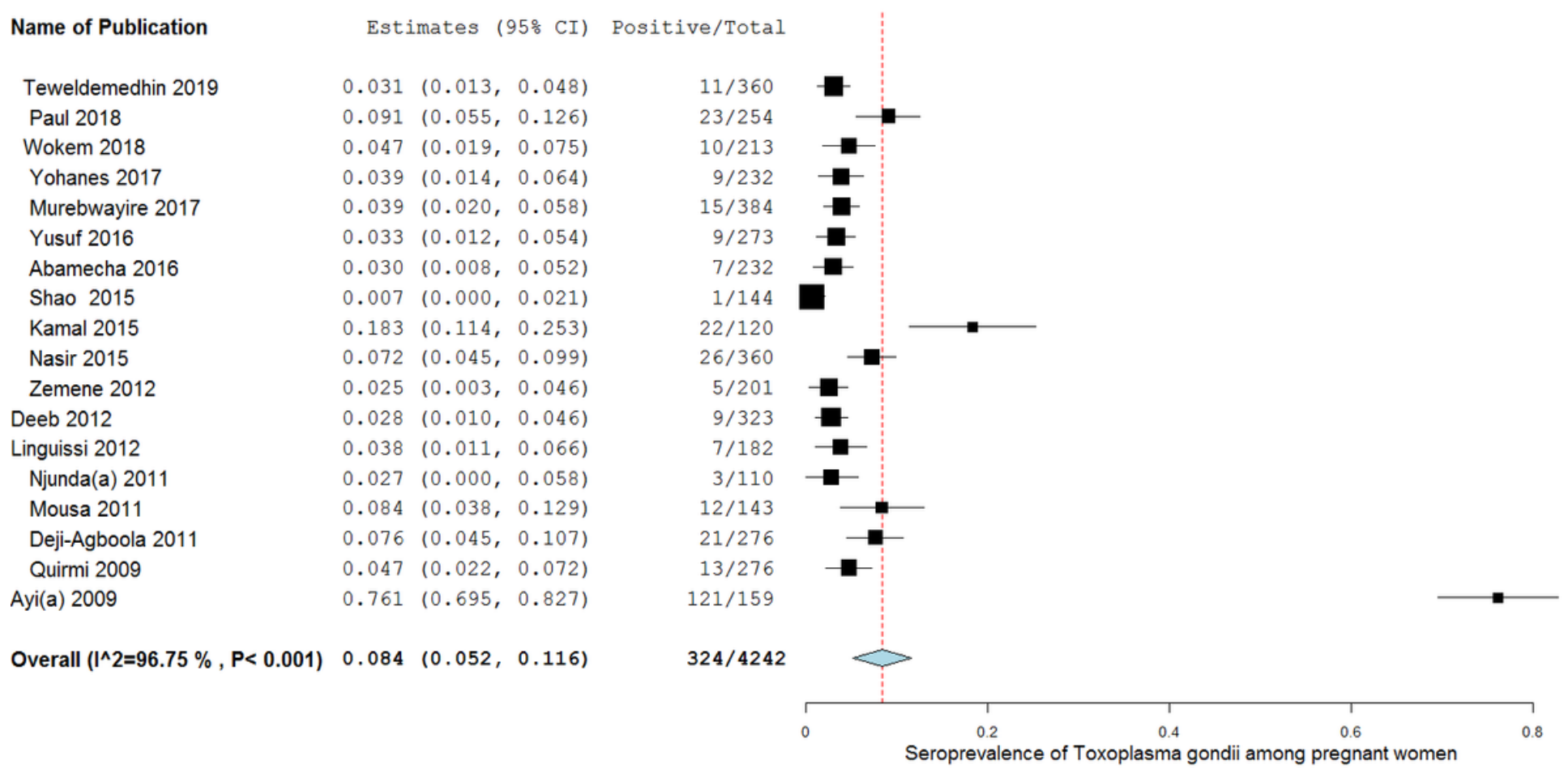

\section{Figure 4}

Forest Plot depicting the polled analysis of 18 studies reporting sero-prevalence of T. gondii among pregnant women measured by $\lg \mathrm{M}$

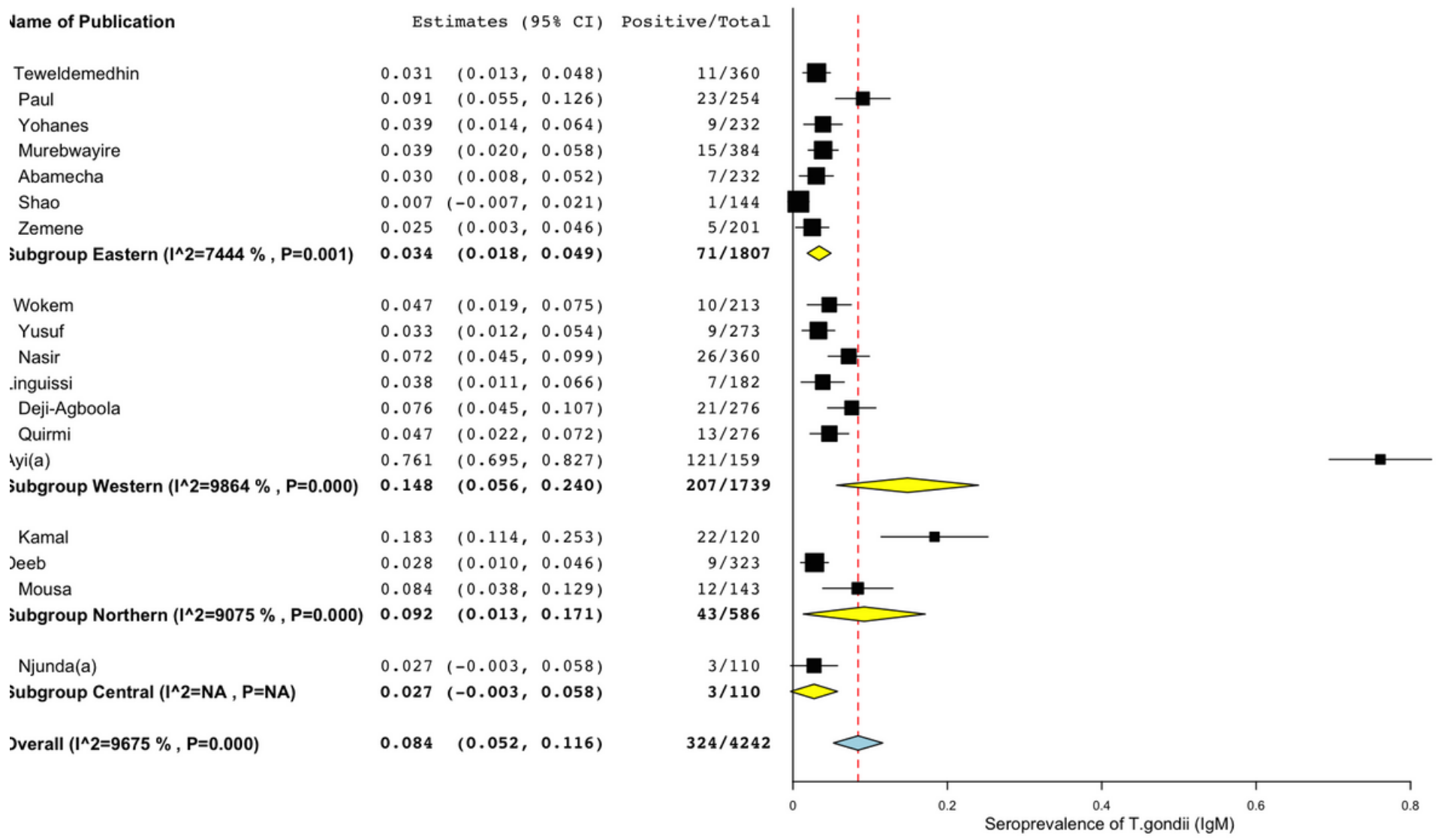


Figure 5

Forest plot depicting sub-group analysis of T. gondii among pregnant women measured by IgM 